\title{
Practice of giving exclusive breastfeeding among the babies of working mothers and house wife mothers- a comparative study
}

\author{
M Hassan ${ }^{1}$, B H N Yasmeen², T U Ahmed ${ }^{3}$, M Begum ${ }^{4}$, A W S Rob ${ }^{5}$, A U Ahmed ${ }^{6}$, H Rahman ${ }^{7}$
}

${ }^{1}$ Dr. Mahmuda Hassan Associate Professor Dept. of Paediatrics Ad-din Medical College, Dhaka

2 Dr. B H Nazma Yasmeen Associate Professor Dept of Pediatrics Nortern International Medical College, Dhaka

${ }^{3}$ Dr. Taslim Uddin Ahmed

${ }^{4}$ Dr. Marium Begum

${ }^{5}$ Dr. A W S Rob

${ }^{6}$ Dr. Ashraf Uddin Ahmed

3 to 6 Assistant Professor Dept. Paediatrics Ad-din Medical College, Dhaka

${ }^{7}$ Dr. Hamidur Rahman

Professor \& Head

Dept. of Paediatrics

Ad-din Medical College, Dhaka

Correspondence

Dr. Mahmuda Hassan

Associate Professor

Dept. of Paediatrics

Ad-din Medical College. Dhaka

E-mail-mahmudahasn@yahoo.com

\section{Abstract}

Objectives : There is gradual reduction of exclusive breast feeding practice as age advances from birth to 6 months. The aim of the study was to see the status of exclusive breast feeding up to 6 month of age, among the babies of working mothers and housewife mothers and also to see different contributing factors among the working mothers for the initiation of breast milk substitute within this period.

Material and Methods : This is a descriptive type of study conducted in Ad. Din Hospital at OPD from $1^{\text {st }}$ January 2008 to $31^{\text {st }}$ December 2009.Total 400 babies were selected, among them 200 were the babies of the working mothers, considered as cases and 200 were the babies the of housewives considered as control. Sampling was done purposively. Then babies of working mothers were divided in to 2 groups according to their age- (Group-I -babies of 3 months \pm 15 days and Group $-\| 6$ months \pm 15 days). Also babies of the housewife mothers were also divided in to 2 groups (Group.l II-babies of 3 months \pm 15 days and Group-IV 6 months \pm 15 days). Each group includes 100 babies. Mothers or caregivers of their babies were interviewed only once for the study with a set questionnaire.

Results : Seventy eight percent (78\%) working mothers were continued exclusive breast feeding up to 3 months \pm 15 days but at the age of 6 months \pm 15 days only $21 \%$ babies were continued exclusive breast feeding. On the other hand at the age of 3 months \pm 15 days $66 \%$ and at 6 months \pm 15 days of age $45 \%$ babies of housewife mothers were continued exclusive breast feeding. Highly significant reduction of exclusive breastfeeding among babies of working mothers (p value $<0.001$ ) and also that of the housewife mothers ( $p$ value $<0.05$ ). Significant number of mothers (more than $80 \%$ ) of both the groups had no or inadequate knowledge about expression and preservation of breast milk ( $p$ value $<0.001$ ). Maternity leave was less than 6 months, 4 months in government organization (GO) and even 45 days for in some non government organization (NGO) were observed.

Conclusion : Exclusive breast feeding up to 6 months of age less among the babies of working mothers even with a good start. Lack of knowledge about expressed breast milk, policy adopted by the employers and maternity leave less than 6 months are the main contributing factors for reduction of exclusive feeding.

\section{Introduction}

Scientific evidence and research have demonstrated the benefits of breastfeeding for child survival, health and nutrition, mental health and child-spacing. Optimal feeding practice should be exclusive breast feeding for the first six months of life and addition of complementary feeding there after with the continuation of breast feeding. ${ }^{1}$ Breastfeeding can save infant's lives and prevent morbidity more than any other intervention strategy. ${ }^{2,3}$

Practices of exclusive breast feeding from birth to 6 months gradually reduces as age advances, it has been observed in a study. ${ }^{4}$ Practicaly working mothers get much more difficulties in giving exclusive breast feeding. While number of new mothers in the workplace increases, an early return to work and inconvenient workplace conditions discourage women from breastfeeding or cause them to discontinue breastfeeding early. ${ }^{5-7}$ Both UNICEF and The World Health Organization (WHO) recommend that the mothers should give exclusive breastfeeding to their babies for at least 6 months. ${ }^{8,9}$ Now a days in many developing countries like Bangladesh females are doing jobs due to the increased financial requirement of the family and as a part of female empowerment. Therefore a working mother is doing multiple jobs at a time like household activities, child rearing etc a job outside home. These working mothers are facing more difficulties in giving exclusive breast feeding when they are going to work at the end of the maternity leave, as because duration of maternity leave is 4 months only at the government level and it is even less at the non government organizations. In Nairobi, Kenya mothers were surveyed between 4 and 12 months of postpartum period and found that $94.1 \%$ cotinued breastfeeding, which was possible by giving opportunities to feed their child during work. ${ }^{10}$ Such flexible work practices are generally not available in all work palaces. The International Labor organization (ILO) recommends a period of maternity leave of not less than 14 weeks ${ }^{11}$ The ILO maternity protection convention 191,2000 recommends provision of paid maternity leave for 18 weeks and keep provision of breast feeding breaks, facility for breast feeding and expression of breast milk at the work place. Unfortunately these recommendations are rarely followed. Another way to facilitate exclusive breastfeeding up to 6 months is to extend the maternity leave to 6 months.

In Norway, the Government provides maternity leave for 42 weeks with full pay or 52 weeks at $80 \%$ pay. In Sweden, the parental leave (shared by mother and father) for 18 months with $90 \%$ salary for the first 15 months. ${ }^{12}$ The length of maternity leave is possibly associated with the duration of breast feeding ${ }^{13,14}$ Breast feeding friendly policies can positively affect breast feeding behavior. However an unfavorable working 
environment, specially for garment sectors, corporate office, even employees of government organizations, can make it difficult to continue exclusive breast feeding up to 6 months. The objective of this study was to identify the status of exclusive breast feeding up to 6 months of babies among working mothers and house wife mothers and also to compare the incidence of exclusive breast feeding status among them.

\section{Materials and Method}

This is a descriptive type of study conducted in Ad- Din Hospital at OPD from $1^{\text {st }}$ June 2008 to $31^{\text {st }}$ December 2009. Sampling was done purposively. Both inborn and out born babies were selected when they were attended the outdoor for routine vaccination or routine follow up or for some minor illnesses. Working mothers of different professions like garment workers, architects, lawyers, working at corporate office, doctors, nurses both from GO and NGO were selected.

\section{Inclusion criteria}

Lacteting mother

- who were doing job at least for 1 year before child birth

- got remuneration monthly

- got maternity leave of any duration

- who had at least 3 antenatal check-up during pregnancy with good counseling regarding exclusive breast feeding up to 6 months of the baby

\section{Exclusion criteria}

- Babies with cleft lip, cleft palate, congenital heart diseases and other congenital malformations

- babies with major illness in neonatal period required hospital admission

- student mothers (college,university) were not considered for the study.

Total 400 babies were selected, 200 were the babies of working mother, considered as cases and 200 were the babies of housewives considered as control. Then babies of working mothers were devided in to 2 groups according to their age- (Group-I -babies of 3 months \pm 15 days and Group-II 6 months \pm 15 days). Also babies of the housewife mothers were also devided in to 2 groups (Group-I II-babies of 3 months \pm 15 days and Group-IV 6 months \pm 15 days). Each group includes 100 babies.Mothers or caregivers of their babies were interviewed only once for the study. A set questionnaire was filled up by talking face to face interview with the mother or caregiver by fulfilling the inclusion criteria. Questions were asked regarding

\section{- status of exclusive breast feeding}

- causes of initiation of breast milk substitute or early weaning

- knowledge or ideas about the expression or preservasion of breast milk

- detail of mothers job-Government /non government / duration of working hour / facility for maternity leave and day care centre (for Case only)

In this study when other than breast milk no water, glucose,drinks or foods are given to the baby i.e in absence of mother baby is on expessed breast milk then the baby is considered as Exclusively breastfed.

$Z$ test was done to compare the findings. In this study $P$ value $<0.05$ was considered as the level of significance.

\section{Results and Observations}

Total 400 babies were selected for this study. Then babies of working mothers (Case) were devided in to 2 groups according to their age-Group-I and Group-II. Babies of housewife mothers (Control) were also devided in to 2 groups Group-III and Group-IV. Each group includes 100 babies.Mothers or caregivers of their babies were interviewed only once for the study. All the babies were came from Dhaka city and its suburbs. Male were $52 \%$ and female $48 \%$. This study showed that $78 \%$ babies of Working mothers continued exclusive breast feeding up to 3 months \pm 15 days in Group I. But at the age of 6 months \pm 15 days only $21 \%$ babies of working mothers (Group II) continued exclusive breast feeding ( $p$ value $<0.001$ ). It is also found in this study that among the babies of house wife mothers $66 \%$ (Group III) were exclusively breast feed up to the age of 3 months \pm 15 days which is reduced to $45 \%$ (Group IV) at the 6 months \pm 15 days ( $p$ value $<0.05$ ). At 3 months \pm 15 days of age only $22 \%$ babies(Group I) were on mixed fed, but at the age of 6 months \pm 15 days of age $79 \%$ babies(Group II) were on mixed fed or started early weaning. On the other hand, at the age of 3 months \pm 15 days, among the babies of house wife mothers $34 \%$ on mixed feeding or on breast milk substitute which was increased in to $55 \%$ on 6 months \pm 15 days of age (Table- I).

Therefore it was found that Working mothers had a good starting of exclusive breast feeding which was sustaining up to the age of 3 months \pm 15 days, but ultimately at 6 months \pm 15 days there is significant reduction of exclusive breast feeding practice $(p<0.001)$

Table I : Number of babies on exclusive breast feeding (EBF)/ mixed feeding(MF) / breast milk substitue (BMS)

\begin{tabular}{|c|c|c|c|c|}
\hline & \multicolumn{2}{|c|}{$\begin{array}{c}\text { babies of working } \\
\text { mothers Case }\end{array}$} & \multicolumn{2}{c|}{$\begin{array}{c}\text { babies of housewife } \\
\text { mothers Control }\end{array}$} \\
\hline Total=400 & $\begin{array}{c}\text { Group I } \\
\text { no=100 }\end{array}$ & $\begin{array}{c}\text { Group II } \\
\text { no=100 }\end{array}$ & $\begin{array}{c}\text { Group III } \\
\text { no=100 }\end{array}$ & $\begin{array}{c}\text { Group IV } \\
\text { no=100 }\end{array}$ \\
\hline Age & 3 months $\pm 15 \mathrm{~d}$ & 6 months $\pm 15 \mathrm{~d}$ & 3 months $\pm 15 \mathrm{~d}$ & 6 months $\pm 15 \mathrm{~d}$ \\
\hline & no (\%) & no (\%) & no (\%) & no (\%) \\
\hline EBF & $78(78 \%)$ & $21(21 \%)$ & $66(66 \%)$ & $45(45 \%)$ \\
\hline MF/BMS & $22(22 \%)$ & $79(79 \%)$ & $34(34 \%)$ & $55(55 \%)$ \\
\hline
\end{tabular}

EBF status among working mothers groups (Case) around 3 and 6 months of age $p$ value $<0.001$

EBF status among housewife mothers groups (Control) around 3 and 6 months of age $p$ value $<0.05$

Table II: Comparison of different job situations of lactating working mothers

\begin{tabular}{|l|c|c|c|}
\hline \multicolumn{1}{|c|}{ Catagory of job } & Govt. jobs & Non govt. job & $\begin{array}{c}p \text { value } \\
\text { (Unpaire } \\
\text { d t test) }\end{array}$ \\
\hline Number of mothers & $22(11 \%)$ & $178(89 \%)$ & $<0.001$ \\
\hline Continued job & $19(86.3 \%)$ & $49(27.5 \%)$ & $<0.001$ \\
\hline $\begin{array}{l}\text { Left or plan to leave the } \\
\text { job }\end{array}$ & $\begin{array}{c}3(\text { Plan to } \\
\text { leave) }(13.6 \%)\end{array}$ & $129(72.47 \%)$ & $>0.05$ \\
\hline $\begin{array}{l}\text { Having Day care } \\
\text { Centre facility at } \\
\text { working place }\end{array}$ & $4(18.18 \%)$ & $15(8.4 \%)$ & $<0.01$ \\
\hline Maternity leave & 4 months & $1.5-3$ months & \\
\hline
\end{tabular}

This table shows significant number of mothers are doing non-government jobs ( $p$ value is $<0.001$ ). Significant number of mothers were from government organizations continued their job ( $p$ value $<0.001$ ). Good number of mothers from non government organizations left or planned to leave the job ( $p$ value is $>0.05$ ). Day care centers are available in only 
$18.8 \%$ in government organizations and $8.4 \%$ in non government organizations $(p$ value $<0.01$ ). From this study it is clear that working women of GOs are more benefited regarding lactation facility than that of the NGOs.

\section{Table III: Knowledge about expression and preservetion of breast milk}

\begin{tabular}{|c|c|c|}
\hline $\begin{array}{c}\text { Knowledge about expression, } \\
\text { preservesion of breast milk }\end{array}$ & $\begin{array}{c}\text { Working mothers } \\
\text { Case }\end{array}$ & $\begin{array}{c}\text { House wife mothers } \\
\text { Control }\end{array}$ \\
\hline No /inadequate knowledge & $177(88.5 \%)$ & $165(82.5 \%)$ \\
\hline Adequate knowledge & $23(11.5 \%)$ & $35(17.5 \%)$ \\
\hline$z$ test/ $p$ value & $<0.001$ & $<0.001$ \\
\hline
\end{tabular}

In both the groups, more than $80 \%$ mothers, did not have any knowledge or have inadequate knowledge about how to express and preserve breast milk for future use (Table III) and these are statistically significant ( $p$ value< 0.001).

\section{Discussion}

In most of the cases breast feeding for a working mother is a conflict between her ability and desire. In recent years there has been a rise in the participation rate of women employment in our country because of the rapid rising of the costs of every household goods, increase literacy rate of the women and awareness about the women's rights, empowerment by the GO and by different NGO.

Several study showed that women who fed their babies with breastmilk enjoyed longer maternity leave in comparison with women who fed formula milk from the beginning. ${ }^{15,16}$ But in our country the practical scenario is opposite. GOs and NGOs are giving 4 months maternity leave with pay, even some NGOs are giving maternity leave only 45 days. Working status had no effect on initiation of breastfeeding, but had an effect on continuation of breastfeeding up to 6 months. Most of the mothers return to work after the end of the maternity leave which is less than 6 months, in some cases it is only 45 days. Unless these mothers get support from their employers and fellow employees, they might give up breast feeding when they return to work or leaving their jobs to continue breast feeding.

In our study working mothers had a good starting and sustaining exclusive breast feeding up to the age of 3 months \pm 15 day, but at 6 months \pm 15 days there is significant reduction of exclusive breast feeding practice $(p<$ 0.001 ). As a result, duration of exclusive breast feeding to the recommended age up to 6 months of age of the baby is affected.

It has been observed in one study that women with higher education, high economic level, lower birth interval and delivery assisted by health personnel had lower duration of breast feeding. ${ }^{17}$ But in this study it is observed that the exclusive breast feeding practice is higher among the working mothers group up to 3 months of age of the baby (78\%) than compared with house wives group (66\%), but the scenario is just reversed at the age of 6 months of the baby, exclusive breast feeding practice is higher among house wives (45\%) than that of the working mothers $(21 \%)$. Also the facilities for day care centre at or near working place is insignificant at present situation in Bangladesh as we observed in this study ( $p$ value $<0.01$ ). Also it has been seen in this study that knowledge and ideas about expressed breast milk is inadequate i,e 177 (88.5\%) and $165(82.5 \%)$ among the working mothers and the housewife mothers respectively. In a study it has been observed that overall knowledge of the medical students regarding breastfeeding was low. ${ }^{18}$

From the analysis of this study we can assume that the knowledge of giving exclusive breast feeding is better among the working mothers, but they did not continue exclusive breast feeding up to 6 months of the baby, because of the lack of knowledge of giving expressed breast milk and also unfavorable environment of the working places. Employers can help those mothers by providing day care centre at or near the work place and by giving break for breast feeding and also help mothers by giving time to express breast milk and store the milk by providing refrigerator at the work place. Besides this health care providers (doctor, nurse, health worker) can teach the mother how to express breast milk, and remove all the misconceptions about the expressed breast milk which will help the working mothers to continue exclusive breast feeding up to 6 months.

As in many developed countries Hong Kong passed through the era when breast feeding was the exception. The nadir for Hong Kong was in 1978 when breast feeding rate was $5 \%$ only. ${ }^{19}$ In one study WHO has stated that only $16 \%$ of mothers in Pakistan exclusively breastfeed for a period of 3 months, as compared to other developing countries where the ratio is higher specialy in Bangladesh (46\%), India (37\%) and Srilanka (84\%). ${ }^{20}$ But in our study exclusive breastfeed for a period of 3 months was (78\%) and $(66 \%)$ among the working mothers and the housewife mothers respectively.

\section{Conclusion}

Exclusive breast feeding up to 6 months of age less among the babies of working mothers even with a good start. Lack of knowledge about expressed breast milk, unfavourable work place enviournment and maternity leave less than 6 months are the main contributing factors for reduction of exclusive feeding up to 6 months of age.

\section{References}

1 World Health Organization (WHO) Breastfeeding : The technical basis and recommendation for action. World Health Organization: Geneva, 1993.

2 Lutter $C(E d)$ : Towards global breast feeding. Washington DC. Institute for reproductive health, Georgetown University, 1990.

3 Sharma R : A comparative analysis of trends and differentials in breast feeding. Washington DC. Institute for reproductive health, Georgetown University, 1990.

4 Hassan M, Tawfique M, Afroz S et al: Status of exclusive breast feeding from birth up to 6 months of age- an observation from Ad-din Hospital. Dhaka Shishu (Child) Hospital Journal. 2007; 23 (1): 7-12.

5 Kearney M H, Cronenwett L. Breast feeding and employment. J of Obstet Gynecol Neonatal Nurs. 1991; 20: 471-480

6 Fein S B, Roe B. The effect of work status on initiation of breast feeding. American Journal of Public health. 1998; 88: 1042-1046.

7 Meek J Y. Breast feeding in the workplace. Pediatric clinics of North America. 2001; 48: 461-474.

8 8. UNICEF. UNICEF Baby Friendly Initiative: Health Benefits of Breast Feeding. http://www.babyfreindly.org.uk (2002).

9 WHO. The Optimal Duration of Exclusive Breastfeeding: Results of a WHO Systematic Review. Geneva: WHO, 2001.

10 Lakati A, Binns C, Stenson M. Breast-feeding and the working mother in Nairobi. Public Health Nutr 2002; 5(6):715-8.

11 Organization IL. Maternity Protection Convention 183.

12 UNICEF. Breast feeding foundation for healthy future, New York, UNICEF Division of communication 1999; pp 4 -9.

13 Visness CM, Kennedy KL. Maternal employment and breast feeding: findings from the 1998. National Maternal and infant health survey. American Journal of Public Health. 1997; 87: 945-950.

14 Hammer LD, Bryson S, Agras WS. Development of feeding practice during the 5 years of life. Archives of Pediatrics and Adolescent Medicine 1999; 153: 189-194.

15 Duckett L. Maternal employment and breastfeeding. NAACOG'S Clin Issu Perinat Womens Health Nurs 1992;3:701-11.

16 Yocca Ch. Workplace support for lactating mothers: a study of the benefits provided by employers in the Hudson Wisconsin area. The research paper. The Graduate College University of Wisconsin, Stout, USA, 2000.0k

17 Giashuddin MS, Kabir M. Duration of breastfeeding in Bangladesh. Indian J Med Res. 2004 ; 119(6): 267-72.

18 Anjum Q, Ashfaq T, Siddique $H$ et al. Knowledge regarding breast feeding practice among Medical Students of Ziauddin University Karachi. JPMA 2007; 57: 48-52.

19 Katcher A, Lanese M. Breastfeeding by employed mothers: a reasonable accommodation in work place. Pediatrics. 1985;88:728-36

20 State of Worlds Children. UNICEF, 2005. p110-113. 